Cybernetics and Systems

An International Journal

ISSN: 0196-9722 (Print) 1087-6553 (Online) Journal homepage: http://www.tandfonline.com/loi/ucbs20

\title{
A Test of the Viable System Model: Theoretical Claim vs. Empirical Evidence
}

\section{Markus Schwaninger \& Christine Scheef}

To cite this article: Markus Schwaninger \& Christine Scheef (2016): A Test of the Viable System Model: Theoretical Claim vs. Empirical Evidence, Cybernetics and Systems, DOI: 10.1080/01969722.2016.1209375

To link to this article: http://dx.doi.org/10.1080/01969722.2016.1209375

\section{曲 Published online: 12 Aug 2016.}

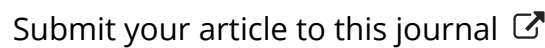

Џll Article views: 1

Q View related articles $₫$

View Crossmark data $\asymp$ 


\title{
A Test of the Viable System Model: Theoretical Claim vs. Empirical Evidence
}

\author{
Markus Schwaninger ${ }^{\mathrm{a}}$ and Christine Scheef ${ }^{\mathrm{b}}$ \\ anstitute of Management, University of St. Gallen, Switzerland; 'bSt. Gallen Institute of Management, \\ Asia, Singapore
}

\begin{abstract}
The Viable System Model by Stafford Beer embodies a theory about the preconditions of organizational viability. This theory has been discussed extensively by the academics and professionals of organizational cybernetics. The theoretical claim of the Viable System Model (VSM) is bold. It asserts to specify the necessary and sufficient preconditions for the viability of any organization. The empirical evidence, to date, amounts to a substantial corpus of case studies from applications that support the claim of the theory. The present contribution leads beyond the status quo. Its purpose is to test the theory empirically, on the grounds of a broad survey and pertinent quantitative analysis. The available data support the hypotheses and therewith corroborate the theory of the VSM. This implies that the VSM is a reliable orientation device for the diagnosis and design of organizations to strengthen their vitality, resilience, and development potential.
\end{abstract}

\section{KEYWORDS}

Empirical test; organization design; organizational health; organizational resilience; organizational viability; test of theory; viable system model

\section{Introduction}

Organization theory is a wide territory, and its landscapes are manifold. The concern of organization science is a generalist one, a quest for an integrative, holistic view on the subject of organized social systems. Over time, however, different schools have evolved and populated the territory, offering diverse views on the subject matter under study. More precisely, the different schools offer distinct perspectives, opposed to agreeing on one monolithic theme. Because this is not a review article, we keep the overview of relevant literature very brief.

Compendia on organization theory show the great diversity of organization science (e.g., Pfeffer 1997; Baum 2002). Aspiring to penetrate this "jungle of theories" (Koontz 1961, 1980) in the context of our small inquiry would be futile. Many review studies have ventured to chart the territory. One example is a work by Hatch (1997), who identifies four major perspectives on organizations in chronological order: classical, modern, symbolic-interpretive, and postmodern. Another example is a book by Bolman and Deal (1991), in which

CONTACT Markus Schwaninger markus.schwaninger@unisg.ch $\Theta$ Institute of Management, University of St. Gallen, Dufourstr. 40a, St. Gallen, CH-9000, Switzerland.

Color versions of one or more of the figures in the article can be found online at www.tandfonline.com/ucbs.

(c) 2016 Taylor \& Francis Group, LLC 
four approaches to understanding and managing organizations-structural, human resources, political, and symbolic-are distinguished.

Similar to these reviews, certain authors have tried to structure the landscape, subsuming different schools under broader perspectives. A synoptic view of that kind is given by Morgan (2006), who structures the high variety of organization science schools through the lens of seven metaphors: e.g., organizations as machines, organizations as cultures, organizations as brains, organizations as political systems, etc.

Finally, Scott and Davis (2007) examine a number of typologies, both deductive and empirically grounded. Thereupon, they propose their own typology for organizational analysis, drawing on the perspectives of organizations as (a) rational systems, (b) natural systems, and (c) open systems. Scott and Davis (2007) also refer to relatively comprehensive models that integrate these different views: Etzioni's structuralist model, the contingency model by Lawrence and Lorsch, and Thompson's multilevel model of organizations. They also recite Stafford Beer's (1964) opus "Cybernetics and Management," which contains a cybernetic theory of organization.

We are referring to only one organization theory, Stafford Beer's Viable System Model (VSM) in its more elaborate form (Beer 1979, 1981, 1984, 1985). That theory is tied to all three perspectives propounded by Scott and Davis (2007): first, it embodies a rational-structuralist view on organizations; second, it is inspired by the structure of a natural system, the human nervous system; third, it incorporates the open systems view, which explicitly includes the environment in the organizational analysis.

We are choosing the theory of the VSM for its distinctive feature: it is the only theory that addresses a highly generic and comprehensive system objective-the viability of an organization-and asserts to establish the necessary and sufficient structural preconditions for such viability. This is a very bold claim. To our knowledge, organization theories generally do not allege knowledge of sufficient conditions, but contend that they only specify necessary conditions for success, high performance, and the like.

Despite its audacious claim, the VSM has, until now, not been refuted on empirical grounds.

The purpose of this contribution is an empirical test of the VSM by means of a sufficiently large sample in order to provide significant results. This is not an endeavor to "prove" the model, which would be futile. Proof is a matter of the formal sciences (mathematics, formal logic), not of the social sciences (Popper 1972, 2002).

The two research questions in this context are "Can the claim of Stafford Beer's Viable System Model be refuted?" and "If not, to what extent is it corroborated by the data?"

This article is structured as follows. First, we will introduce the theory of the VSM. This will lead us to the research gap to be addressed-a test of 
the VSM on a broad basis in "Tests of the Theory, Past and Planned." Next, the hypotheses are developed, and following that, the methodology is designed in view of the purpose, and the research questions are outlined. Thereafter, the data analysis is carried out. Finally, "Implications and Synthesis" provides a synthesis, emphasizing the implications of the results and an outlook on future work on the topic.

\section{Theory}

The VSM, which will be tested here, is based on Stafford Beer's theoretical writings, namely Beer $(1979,1981,1984,1985)$, as well as Espejo and Reyes (2011) and Pérez Ríos (2012). ${ }^{1}$ In these sources, the model is presented both verbally and graphically. ${ }^{2}$ With Beer, we conceive of the attribute "viable" as "capable of living," and define "viability" as the ability to maintain a separate existence (Simpson and Weiner 1989, p. 588, Vol. XIX). The fundamental theoretical claim of Stafford Beer is that the VSM determines the necessary and sufficient conditions of organizational viability. These conditions and their implications are defined as follows.

\section{First - Components of the Model}

An organization is viable only if it has a management system, the components $^{3}$ of which are specified as follows. For a graphical representation see Appendix I:

System 1: The management, i.e., the regulatory capacity of the basic units (e.g., divisions or business units of a company). ${ }^{4}$ The basic units with their regulatory capacities are called "primary units." These widely autonomous and adaptive wholes conduct and optimize the daily business-in the "here and now."

System 2: The coordination function, which dampens oscillations and enhances self-regulation. Examples are the information systems, operative plans, schedules and programs, teams, internal service and support units, standards of behavior, knowledge bases, and a great part of communication.

System 3: The operative management of the organization as a whole. It is responsible for resource allocation and fosters cohesion, assuring a global

\footnotetext{
${ }^{1}$ Besides these basic writings, the literature includes many appreciations of the VSM and accounts of its applications. It would be beyond the reach of this article to provide a complete list of these sources. Here is an abridged set of references: Malik 2008; Jackson 1988; Espejo and Harnden 1989; Brocklesby and Cummings 1996; Espejo et al. 1996; Adam 2001; Christopher 2007; Hoverstadt 2008; Türke 2008; Leonard 2010; Pérez Ríos 2012. A more detailed but earlier overview can be found in Schwaninger 2009. For VSM-based case studies see the next section.

${ }^{2}$ The mathematical, set-theoretic version is published in Beer (1962).

${ }^{3}$ According to the established convention in the cybernetics community, these components are usually simply called "Systems" to emphasize their systemic nature. In the sections of the hypotheses and data analysis we treat these "Systems" as "Components."

${ }^{4}$ We are adhering to the convention established by Stafford Beer $(1981,1985)$, by which the regulatory function (System 1) and the operation are distinguished analytically. The underlying logic is that System 1 is a function, not a person. Certain authors, e.g., Espinosa and Walker (2011), distance themselves from that convention.
} 
performance optimum, which often deviates from the local optima in the primary units: The "executive management" with core functions such as human resources and finance.

Relationship Systems 1-3 (vertical channel): Negotiation of goals and resources-accountability, management by objectives, budget control, management by exception, intervention (only if the cohesion of the whole organization is threatened).

Relationship Systems 1-2-3: Attenuation of complexity, filtration of information coming from basic units to relieve System 3. Communicational damping of variety ${ }^{5}$ and sustenance of organizational cohesion.

System 3*: The auditing channel, in which the information flowing through the channels 1-3 (vertical command and alignment channel: resources, responsibility) and 1-2-3 (lateral channels: coordination), is supplemented by this function of monitoring and (sporadic) validation. The information flowing through these channels is scrutinized for its quality and reliability and complemented by means of direct access to the basic units. Examples are monitoring and auditing, "management by wandering around," social and cultural activities, informal communication. ${ }^{6}$

System 4: The long-term orientation toward the future and in respect of the environment (ecological, social, economic-technological). Modeling and diagnosis of the organization in its environment. Strategic exploration of potential spaces of action. Examples are corporate development, strategic management, research and development, the creation of new capabilities, knowledge and wisdom.

Relationship System 3-4: Interaction of short- and long-term as well as internal and external perspectives, processes of strategizing. Components 3 and 4 form a homeostat, i.e., a body of mutual adaptation striving for stability. System 5: Establishes an equilibrium between present and future orientation, in a virtually timeless (very long term) horizon, and between internal and external orientation. Determines the identity of the organization and its function in the greater reference system. Examples include the supreme values, norms and principles, which govern the system, i.e., the ethos of the organization.

Relationship Systems (3-4)-5: Moderation of the interactions of Components 3 and 4, solution or dissolution of conflicts between the distinct logics of these Systems.

The management system outlined here (all too) briefly is a set of homeostats of mutually adapting components (e.g., 1-3, 3-4, etc.), in quest

\footnotetext{
"Variety" is a measure for complexity; it denotes the repertoire of behaviors of a system (Ashby 1956). More precisely, Variety is defined as the number of distinct states or behaviors that a system can assume (Potential Variety) or assumes (Actual Variety). In our data analysis, we are subsuming the items for System $3^{*}$ under System 3, because statistically we could not ascertain any empirical difference between the two constructs.

${ }^{6}$ In our data analysis, we are subsuming the items for System $3^{*}$ under System 3, because, statistically, we could not ascertain any empirical difference between the two constructs.
} 
of stability. That stability is achieved by a balance of the varieties of the component systems. For example, imbalance is the case, if a low-variety ("weak") System 4 interacts with a high-variety ("strong") System 3. A functioning homeostat will correct that imbalance; it will show a tendency to equate the varieties. If not, a logically higher-level instance (System 5) will have to intervene.

\section{Second - Implications for Organizational Diagnosis and Design}

Deficiencies in the texture outlined previously will impair or endanger the viability of the organization. Such deficiencies could be missing functions, insufficient capacity of the functions, or faulty interaction among them, in particular, gross or proliferating imbalances in variety.

\section{Third - Recursion}

The structure laid out manifests itself recursively at the various planes of an organization. It comprises autonomous units within autonomous units: a viable organization is made up of viable units and it is itself embedded in more comprehensive viable units. For example, in a company, the same structural principles should be discernible at the different levels of the company, divisions, business units, etc., and on a higher rank, if extant, in the group of companies.

Each unit, inasmuch as it is producing the organization's task, rather than servicing or supporting this producing, replicates, in structural terms, the totality in which it is embedded: It has all the aforementioned components to be able to manage, from start to finish, the processes of the purpose for which it exists. Hence, the functions of management and control, in the VSM, are spread throughout the organization, which gives rise to selforganization and organizational effectiveness (Jackson 2000).

In our empirical study, we are looking at wholes, which are usually entire companies, but which can also be parts thereof, such as divisions or business units. ${ }^{7}$ This is a logical consequence of the recursion principle just introduced. We left open to the respondents of our survey to refer to either, in filling in the questionnaire.

\section{Tests of the Theory, Past and Planned}

In the empirical sciences there are two ways of testing a theory. One is by efforts of verification and confirmation, the other by attempts of falsification (Seiffert and Radnitzky 1974). In the first case, empirical evidence is gathered

\footnotetext{
${ }^{7}$ We are not considering support functions; these are not primary units.
} 
and accumulated, which is in agreement with the theory. This logic of corroboration imputes that more confirmation implies a stronger theory.

The second approach originates from Popper's (2002) falsification principle: A theory holds as long as it has not been falsified, i.e., refuted on the basis of scientific argument. Hence, the progress of science is a function of successive tests and refutations along an evolutionary process (Popper 1972). The falsification criterion is widely considered to be stronger than the confirmation criterion. Therefore, we will test the theory of the VSM according to the former. ${ }^{8}$

With respect to the VSM, tests of the theory beyond single case studies have been rare. Many reports on successful uses of the VSM have been presented. These are often not taken in hand from a testing logic, but rather motivated by a desire to convince others of the utility of the model. Such cases of "tests" via confirmation emanate from an interest to know whether the theory works, and they are a necessary complement to the tests following a falsification logic.

Many of these cases refer to corporations (e.g., Beer 1979; Espejo and Harnden 1989; Gmür, Bartelt, and Kissling 2010), or parts thereof (e.g., knowledge teams, in Frost 2005), public organizations (Beer 1970; Leonard 1989), local or regional settings (Türke 2008; Schwaninger 2012; Espinosa and Walker 2013), nations (Beer 1989; Willemsen 1992), or at multiple recursions (Beer 1979; Schwaninger 2015).

Several subject matters have been addressed, e.g., sustainability (Espinosa and Walker 2006; Schwaninger 2006b; Espinosa, Harnden, and Walker 2008), the analysis of information (Preece, Shaw, and Hayashi 2013), disaster management (Reissberg 2010), project management (Schwaninger and Körner 2004), virtual organizations (Schwaninger and Friedli 2011), and the potential of the VSM for organizational diagnosis and design (Willemsen 1992; Schwaninger 2006a, 2012). Other authors have focused on the methodology for the application of the VSM (Espejo and Harnden 1989; Espejo and Reyes 2011; Pérez Ríos 2012), some on combinations of the VSM with other methodologies (Herrmann et al. 2008; Schwaninger and Pérez Ríos 2008; Elezi et al. 2014).

To our knowledge, unsuccessful or failing applications of the VSM have not been reported in the literature.

Also, however, critiques of the model have been brought forth. The main critique as formulated by Ulrich (1983), e.g., disparages the VSM as the epitome of a "cybernetic logic," which, in the critic's view, produces inhuman conditions, incapacitating and dominating humans. Another critique is that the model is too general (Amey 1986). Neither type of criticism is of the empirical type, but rather deductive, and they are often normative, not descriptive. Given the

${ }^{8}$ This article approaches the VSM from a social science, (empirical science) perspective. Hence, we reemphasize: we cannot and do not claim to "prove" the model to be "right," because proof is a matter of the formal sciences only. 
empirical nature of the present study, these critiques are not of primary concern here. For those interested, an analysis and response to these conjectures can be found in Schwaninger (1989) and Jackson (2000).

Our work builds on the principle of falsification. As suggested above, attempts at falsification are, in principle, the most powerful tests of theories. With regard to the VSM, only very few endeavors of that kind have been undertaken: two dissertations have engaged in bold ventures that pioneered tests of the model on a broader basis. Crisan Tran (2006) was the first to present a test based on a representative survey. She asked the question with regard to if and to what extent the structural components of the VSM are a precondition for the viability of companies. Given the resource limitation of a dissertation, she limited her sample to a set of startups. Her study did not falsify the model. The results were not unambiguous, but she found that System 4 has a significant positive influence on the viability of a startup. Frost (2005), in his dissertation, analyzed a sample of communities of practice at Siemens AG. The findings of his field study indicate a strong correlation between the parameter values for the structural components of the VSM and the long-term existence of these communities.

Both of these authors have not succeeded in falsifying the VSM. The empirical evidence provided by them, however, is limited, mainly due to scarcity of data. This has motivated us to continue the empirical work, making a new effort to test the VSM.

\section{Hypotheses}

Our research question led to the development of a set of hypotheses, which we are presenting in three subsets, (a) the general working hypothesis, (b) the hypotheses linked to the components of the model, and (c) overarching hypotheses.

\section{General Working Hypothesis}

This is our general working hypothesis:

In the sense of the VSM, the better the management system functions, the stronger is the viability of the respective organization.

Or, more precisely:

The functional level of the management system of an organization is positively associated with the viability of that organization.

We derived eight hypotheses to be tested, referring to the components of the management system. 


\section{Hypotheses Linked to the Components of the Model (1 to 5) and their Interrelationships}

Hypotheses 1 to 5 revolve around the question of whether the theory of the VSM can be upheld:

H1: An organization's strength of component 1 is positively associated with its viability.

$\mathrm{H} 2$ : An organization's strength of component 2 is positively associated with its viability.

H3: An organization's strength of component 3 is positively associated with its viability.

H4: An organization's strength of component 4 is positively associated with its viability.

H5: An organization's strength of component 5 is positively associated with its viability.

\section{Overarching Hypotheses (6 to 8)}

Hypotheses 6 to 8 deepen the topics of Hypotheses 1 to 5 . Different from the analysis of the levels of development (also: "functional levels") of the individual components, as carried out here, we are now looking at the whole of the components:

H6: The number of strongly developed components is positively associated with the viability of the respective organization.

In this hypothesis, we address the number of components that show high values, not values of individual components, as a factor of viability. Each component was classified as high and coded as 1 when the value exceeded 3 (out of a 5 -point scale) and coded as 0 otherwise. The final measure was a count variable.

H7: The overall level of development of all components is positively associated with the viability of the respective organization.

Here, we look at the average of all values for the development of components 1 to 5 , as a source for increasing viability.

H8: The variance among the values for the individual components is negatively associated with the viability of the respective organization.

This hypothesis assumes that big differences in the values for components 1 to 5 result in lower viability, and vice versa. We measured these differences as the standard deviation between the values of the five components.

We are aware that these hypotheses are focused on the management subsystems of the model. The wealth of relationships, which we have tried to delineate in the statement on the theory, in cursory fashion, is not fully captured in the hypotheses. We incorporated many of these relationships under the respective components, for example, the 3-1 relationship under 
“Component 3" (see Appendix II), but by and large, a more extensive and explicit consideration of the relational features would have been desirable. We incurred that reduction, merely to make the difficult topic under study amenable to a first survey. Extending the set of hypotheses leading to an expansion of the questionnaire would not have been a feasible alternative. We start with this liability, accepting the obvious likelihood of critique.

\section{Methodology}

The outstanding merits of Crisan Tran (2006) and Frost (2005) are in making the VSM accessible to quantitative analysis for the first time. Our study builds on their work.

We chose the methodology of a direct survey. For that purpose, we elaborated a questionnaire that was theory driven, i.e., based on the theory of the VSM. Our target group for the inquiry was a set of business managers or staff people who had a relatively good overview of a whole primary unit (company, division, business unit). With a preliminary electronic inquiry, using a web-based questionnaire, we obtained a response of 53 randomly selected respondents. On the basis of analysis of that first run, we elaborated the definitive questionnaire. We mainly learned that the number of items, which had been excessive in the first version of the questionnaire, could be reduced by roughly $35 \%$.

The definitive questionnaire was used at the 5 th Business Congress at the School of Management, Organizational Development and Technology, of the Alpen-Adria University, Klagenfurt, Austria. We had targeted that audience, because, given the topic, we needed persons who had a good understanding of their companies or business units. That event was an excellent opportunity for the survey. As the congress gathered entrepreneurs and managers of all industries and company sizes, it was the most suitable occasion to receive responses from a random sample. We collected 349 complete questionnaires, 261 of which met our quality criteria, i.e., they were usable for the data analysis and did not have missing data. ${ }^{9}$

Respondents in their majority were higher and top managers, including chief executive officers and owners of companies.

We are aware that this sample is not perfect: we could not abide by the ideal of building it from scratch and on an unambiguously defined population; our criterion was getting access to a reasonable, diversified set of qualified people. Two clues indicate that via another path we would hardly have succeeded in reaching a relatively large sample: first, an earlier survey of comparable complexity about the same topic attained only 104 completed questionnaires, despite great efforts for data acquisition (Crisan Tran 2006). Second, no other

\footnotetext{
${ }^{9}$ Of these questionnaires, 11 came from organizations in the public sector and nonprofit organizations. In the data
} analysis, the results did not change when this subset was separated from the rest of the sample. 
researcher had ever succeeded in gathering a reasonable sample to study the topic at hand. Hence, for a start, this sample should be acceptable.

The questionnaire showed 40 items measured, as a rule, by Likert scales or single-item-dichotomies for the independent variables. Fourteen items measured the dependent variables. The items are listed in Appendix II. The original questionnaire was in German, and is available from the first author.

The battery of items for the independent variables was constructed according to the logic of functions of the components of the VSM, as specified above, in the theoretical outline of the model. The items for the dependent variables measure different aspects of culture as indicators of viability; details are specified following.

Congruent with Hofstede $(1980,25)$, we conceive of culture as "the collective programming of the mind which distinguishes the members of one human group from another." This definition was chosen from the great variety of concepts of culture in the literature (Eagleton 2000; Schein 2010) because it converges on the nucleus shared by many pertinent definitions. ${ }^{10}$

We do not address culture in general, but organizational culture, as a proxy for the viability of an organization. The underlying assumption is that a variety of features of organizational culture are reliable indicators of organizational viability (Kotter and Heskett 1992; Sterman 2000; Gómez Roldán, and Bray 2009; Moon, Quigley, and Marr 2012). Or, as Sims, Fineman, Gabriel $(1993,178)$ maintain, that "management in Western organizations have looked increasingly at corporate culture as the key to organizational success." This does not imply that the strength of a culture would necessarily be correlated with effectiveness (Schein 1984; Kotter and Heskett 1992).

In our questionnaire, 11 items with regard to the construct of organizational culture were measured on an Osgood semantic differential rating scale, between polar opposites such as "open" and "closed." These represent the dimensions of culture as indicators of viability and are documented in Appendix III. The extremes to the left form an ideal type of a culture of viability, whereas the extremes on the opposite side represent a nonviable culture. The scale of the measurements between visualizes that "viability" is not a dichotomous concept. It is, rather, a concept of gradual manifestations.

The extreme attributes were chosen on the basis of a literature analysis. Our inquiry resulted in the following pairs of attributes:

- Open-Closed: Organizational longevity is a function of openness, in that "new concepts and knowledge will flow through the company ... on an everyday basis." (de Geus 1997, 103; see also Foster and Kaplan 2001). More generally, and in terms of thermodynamics, open systems "can maintain themselves in a state of high statistical improbability" (Von Bertalanffy

\footnotetext{
${ }^{10}$ We do not use Hofstede's measures of culture, because these are dedicated to a different research issue than ours: the screening of cultures in different countries.
} 
1968, 143). This explains the current shift of cultures toward more openness (Berman 2012).

- Adaptive-Unadaptive: In the literature of system theory and cybernetics, adaptiveness to changing situations is the number one feature of viable systems in general (Ashby 1952; Rapoport 1986), and companies in particular (Foster and Kaplan 2001), denoting a system's behavior to improve its chances of survival (Mitchell 2009, 13).

- Learning-Nonlearning: Learning, a system's capacity to enhance its action potential (Senge 1990), is a crucial factor for the viability of an organization on its path of evolution (Jantsch 1980). "Success in the marketplace increasingly depends on learning" (Argyris 1992, 84), and learning occurs at all three levels, individual, group, and organization (Bontis, Crossan, and Hulland 2002).

- Moral-Immoral: It was established by Kant (1911) that not following the law of morality is self-defeating and, therefore, contrary to reason. The ethical orientation is a crucial factor for both an organization's assurance of its existence and the life-enhancing role of its value generation (Ulrich 2010). Data of Grisaffe and Jaramillo (2007) show a clear association of progressive organizational ethics and long-term business viability. Also analyzed on the basis of case studies are how ethical breakdowns "brought about the implosion of viable companies" (Jackson, Wood, and Zboja 2013, 233).

- Cooperative-Egoistic: Cooperation has long been identified as a factor of longevity for social systems. Cooperation with fellow group members is essential to survival (Bowles and Gintis 2011), breeding a "dividend" in terms of a higher propensity for survival (Rapoport 1998; Bowles and Gintis 2011). This holds for both intra- and interorganizational joining of forces for common benefit under changing conditions (Burns and Stalker 2001). Lawrence and Lorsch (1967) discerned the collaboration of subsystems as the essence of integration to a viable system.

- Coherent-Incoherent: It is that integration that ultimately generates a coherent whole (Lawrence and Lorsch 1967). A healthy culture saves energy, entailing organizational effectiveness (Deal and Kennedy 1982). Coherence has also been explained in terms of employee continuity (Heskett 2012) and harmony, which Harmon and Jacobs (1985) entitled the "power of organization." Fragmentation and inconsistency entail frustration and loss of energy while compromising performance (Deal and Kennedy 1982).

- Customer-oriented-Self-centered: The raison d'être of a company is the solution of customer problems (Gälweiler 2005): "To satisfy the customer is the mission and purpose of every business." (Drucker 2001, 24). Empirical evidence shows that "companies that fail to recognize the importance of the customer will face serious problems to their financial health and corporate viability." (Bleuel and Stanley 2007, 41). However, healthy 
cultures thrive on "a core that emphasizes service to customers" (Kotter and Heskett 1992, 57), while an inward focus tends to usher in the decay of a firm (Deal and Kennedy 1982).

- Modest-Arrogant: According to moral theory, modesty is a virtue and arrogance is a vice. Humility is used as a synonym of modesty, with a connotation of unpretentious and candid behavior. In particular, family companies that show exceptional records of viability thrive on modesty together with reliability and continuity (Haasis 2007; Strunk 2011; May 2012). In contrast, the arrogance of managers is a major factor that can jeopardize even long-held performance highs (Kotter and Heskett 1992).

- Long-term oriented-Short-term oriented: A company "organized around the purpose of perpetuating itself as an ongoing community ... has the longevity of a river." (de Geus 1997, 102; see also, Deal and Kennedy 1982). "Strong firms assign precedence to the long-term over the short-term imperatives" (Schwaninger 2009, 64). The best firms bet on a long-term orientation; for example, at Nestlé, the long view is taken as a main strength of the company. Short-termism is short-lived.

- Ecologically responsible-Ecologically irresponsible: Long before the United Nation's definition of "sustainability" came out (Brundtland 1987), philosopher West Churchman (1968) called on the "ethics of whole systems," discerning that "none is so fundamental as the ethical postulate that we are morally obliged to meet the demands that coming generations would have imposed upon were they able to speak to us today." (p.15f.). Other authors have added that this is also a matter of life and death for companies, as it is for humanity (Meadows, Meadows, and Randers 1972; Woodford 2014). Social sustainability is equally important (see e.g., Wuffli 2016), but it has been underresearched (Pfeffer 2010).

These polarities represent a long-range perspective. Let us take certain companies that show an attribute of nonviable cultures, e.g., a lack of ecological or social responsibility, and yet are successful: is the measurement attribute wrong? The answer is in a time lag, or a precontrol relationship ${ }^{11}$ that is invisible: the path of success of that company can endure only until it is disrupted as a reaction to the irresponsibility. Equally, if a company behaves immorally and yet is successful, that does not cancel out the law that binds morality to viability: the consequences of immoral behavior-if it is strong and sustained-will tend to annihilate the successes sooner or later.

As far as independent variables of the study are concerned, they are concretized in the questionnaire, e.g., in case of System 1: Responsibility for profit and loss, for market position, for investments, for human capital, and the level of autonomy. The list of constructs and items used in our questionnaire, with

\footnotetext{
${ }^{11}$ For details on the concept of precontrol, see Schwaninger $(2009,51,77 f$.$) .$
} 
the questions in abbreviated form, is documented in Appendix II. The statistical analysis was performed with the Stata software.

\section{Data Analysis}

\section{Company Size}

Out of 261 cases, the distribution according to size was as follows:

- Fewer than 50 persons: $N=80(30.7 \%)$

- 50 persons or more: $N=181(69.3 \%)$

The official firm count indicates that $87.3 \%$ of Austria's firms have 1 to 9 employees, whereas only $2.1 \%$ have 50 or more (Hameseder and Zach 2013, 23). In other words, the sample of our study shows a bias toward larger companies. For the present inquiry, the accent on relatively large companies was not only a fact, but a necessity. The Crisan Tran (2006) had shown severe difficulties of respondents, entrepreneurs from exclusively young firms, to distinguish between the functions of Components 3, 4, and 5 of the VSM. ${ }^{12}$ Using the $t$-test, the data showed no significant statistical differences between the two partial samples. In other words, the results of the study are applicable to companies of all sizes.

\section{Components of the Management System}

The statistical analysis indicated that all five components ${ }^{13}$ are not only different theoretically but also empirically. Hence, they can be tested separately. To evaluate the appropriateness of our five-factor measurement model, we conducted a confirmatory factor analysis (CFA). We estimated a CFA that included the five latent components as specified in the theoretical model. The CFA provided an acceptable fit to the data (Chi2 $(730)=1434.80, p<0.001$, $\mathrm{CFI}=0.80$, RMSEA $=0.06$ ), indicating that convergent validity could be achieved. Further, all the factor loadings for the measurement model are significant, confirming the factor structure (Shook et al. 2004).

As test of discriminant validity for our latent components, we specified several alternative models combining the different components into four, three, two, and one latent construct. The model fit statistics for these alternative models were weaker than for our proposed five-factor model, showing that the five components are also empirically distinct and not only theoretically.

Finally, the independent and dependent variables showed high consistency among the items. The Kronbach's Alphas all ranged between 0.74 and 0.84 . Given the consistency between the questions, we formed the components 1 to 5 from the averages of the respective sets of questions.

\footnotetext{
${ }^{12}$ Personal communication of Cristina Crisan Tran.

${ }^{13}$ System $3^{*}$ was subsumed under System 3 because we were not able to differentiate the two components in the Confirmatory Factor Analysis.
} 


\section{Overview of Statistical Results}

Table 1 shows the descriptive statistics and correlations of all variables. None of the correlations is above the recommended level of 0.65 , which is a common threshold for survey research (Tabachnick and Fidell 1996; Chadwick and Super 2014) providing support that our results are not biased by multicollinearity.

Considering the five components, which are hypothesized to influence the viability of the organization, descriptive statistics show that the average scores across the five components are relatively low. The average scores across the five components range from 1.40 to 2.44 . Among the organizations, there are only four that have four pronounced components (defined as scores $>3), 15$ organizations that have three pronounced components, 34 organizations that have two pronounced components, 88 organizations that have one pronounced component, and surprisingly, there are 212 organizations that do not have any pronounced component. This last observation hints to the overall assumption of the VSM that multiple components are necessary to make up a viable organization. However, the hint cannot give a clue about the sufficient preconditions for viability: that will be the object of the following testing of hypotheses.

\section{Analysis of Hypotheses 1 to 5}

Table 2 provides a summary of the statistical results concerning Hypotheses 1 to 5 . As shown in that table, all components, with one exception (Component 3), show a significant effect in direction of a culture of viability. The construct "organizational culture" is, with high significance, a function of the degree to which components 1, 2, 4, and 5 are developed. In other words, Hypotheses 1, 2, 4, and 5 are clearly supported whereas Hypothesis 3 is rejected. The negative relationship between component 3 and organizational culture is surprising at a first glance and will be discussed in greater detail in the "Implications and Synthesis" section.

\section{Analysis of Hypotheses 6 to 8}

Tables 3 and 4 provide a summary of the statistical results concerning Hypotheses 6 to 8 . The results of our analyses lead to the following conclusions. The more the components of the management system show a high level of development, the greater are the values for organizational culture qua viability (Table 3). Thus, Hypothesis 6 is supported. Further, the higher the overall functional level of components 1 to 5 , the higher will be the effect on organizational culture qua viability (Table 4). Hence, also Hypothesis 7 is supported. Finally, higher deviations among the functional levels of Components 1 to 5 do 
Table 1. Descriptive statistics and correlations.

\begin{tabular}{|c|c|c|c|c|c|c|c|c|c|c|c|c|c|c|}
\hline & & Mean & SD & 1 & 2 & 3 & 4 & 5 & 6 & 7 & 8 & 9 & 10 & 11 \\
\hline 1 & Component 1 & 2.18 & 0.75 & 1.00 & & & & & & & & & & \\
\hline 2 & Component 2 & 1.89 & 0.50 & $0.28^{* * * *}$ & 1.00 & & & & & & & & & \\
\hline 3 & Component 3 & 1.40 & 0.47 & $0.25^{* * *}$ & $0.5^{* * *}$ & 1.00 & & & & & & & & \\
\hline 4 & Component 4 & 2.15 & 0.71 & $0.23^{* * *}$ & $0.5^{* * *}$ & $0.6^{* * * *}$ & 1.00 & & & & & & & \\
\hline 5 & Component 5 & 2.44 & 0.82 & $0.22^{* * *}$ & $0.5^{* * *}$ & $0.5^{* * *}$ & $0.6^{* * *}$ & 1.00 & & & & & & \\
\hline 6 & Number of strongly pronounced components & 0.61 & 0.89 & $0.44^{* * *}$ & $0.6^{* * *}$ & $0.1^{*}$ & $0.6^{* * *}$ & $0.38^{* * * *}$ & 1.00 & & & & & \\
\hline 7 & Total score of components & 9.75 & 2.78 & $0.56^{* * *}$ & $0.6^{* * *}$ & $0.8^{* * *}$ & $0.8^{* * *}$ & $0.81^{* * *}$ & $0.24^{* * *}$ & 1.00 & & & & \\
\hline 8 & Standard deviation of components & 0.60 & 0.27 & $0.42^{* * *}$ & $0.30^{* * * *}$ & 0 & $0.5^{* * *}$ & $0.48^{* * * *}$ & $0.61^{* * * *}$ & $0.40^{* * *}$ & 1.00 & & & \\
\hline 9 & Culture & 2.32 & 0.74 & $0.37^{* * *}$ & $0.5^{* * *}$ & $0.4^{* * *}$ & $0.4^{* * *}$ & $0.48^{* * *}$ & $0.47^{* * *}$ & $0.56^{* * *}$ & $0.35^{* * *}$ & 1.00 & & \\
\hline 10 & Firm size & 2'928.18 & $12^{\prime} 802.28$ & $0.10+$ & $-0^{*}$ & -0 & -0 & -0.09 & -0.08 & -0.03 & -0 & $0.1^{*}$ & 1.00 & \\
\hline 11 & Firm age & 53.08 & 81.34 & 0.08 & -0 & 0 & 0.1 & -0.04 & 0.01 & 0.03 & -0 & 0 & 0.10 & 1.00 \\
\hline
\end{tabular}

Note. Standardized beta coefficients: $+<0.10 ;{ }^{*}<0.05 ;{ }^{* *}<0.01 ;{ }^{* * *}<0.001$. 
Table 2. Statistical results for Hypotheses 1 to 5.

\begin{tabular}{|c|c|c|c|c|}
\hline & \multirow{2}{*}{$\begin{array}{l}\text { All firms } \\
\text { Model } 1\end{array}$} & \multirow{2}{*}{$\frac{\text { Large and medium-sized firms }}{\text { Model } 2}$} & \multirow{2}{*}{$\frac{\text { Small firms }}{\text { Model } 3}$} & \multirow[t]{2}{*}{ Hypotheses } \\
\hline & & & & \\
\hline Constant & $1.992^{* * *}$ & $2.156^{* * *}$ & $1.924^{* * * *}$ & \\
\hline Firm age & 0.000 & 0.000 & 0.000 & \\
\hline Firm size & $0.065^{* * *}$ & $0.043+$ & 0.085 & \\
\hline Component 1 & $0.154^{* * *}$ & $0.136^{* *}$ & $0.165^{*}$ & H1 supported \\
\hline Component 2 & $0.206^{* * *}$ & $0.249^{* * * *}$ & $0.190^{* *}$ & H2 supported \\
\hline Component 3 & $-0.059+$ & -0.003 & $-0.190^{*}$ & H3 rejected \\
\hline Component 4 & $0.131^{* *}$ & $0.163^{*}$ & 0.092 & H4 supported \\
\hline Component 5 & $0.238^{* * *}$ & $0.183^{*}$ & $0.304^{* * *}$ & H5 supported \\
\hline$N$ & 261 & 181 & 80 & \\
\hline R2 & 0.485 & 0.483 & 0.526 & \\
\hline
\end{tabular}

Note. Standardized beta coefficients; $+<0.10 ;{ }^{*}<0.05 ;{ }^{* *}<0.01 ;{ }^{* * *}<0.001$.

Table 3. Statistical results for Hypothesis 6.

\begin{tabular}{|c|c|c|c|c|}
\hline & All firms & Large and medium-sized firms & Small firms & Hypotheses \\
\hline & Model 1 & Model 2 & Model 3 & \\
\hline Constant & $1.768^{* * *}$ & $1.931^{* * *}$ & $1.609^{* * *}$ & \\
\hline Firm age & 0.000 & 0.000 & 0.000 & \\
\hline Firm size & $0.059^{* * *}$ & 0.037 & $0.102+$ & \\
\hline $\begin{array}{l}\text { Number of strongly } \\
\text { pronounced components }\end{array}$ & $0.472^{* * *}$ & $0.456^{* * *}$ & $0.496^{* * *}$ & H6 supported \\
\hline$N$ & 273 & 181 & 80 & \\
\hline R2 & 0.278 & 0.219 & 0.404 & \\
\hline
\end{tabular}

Note. Standardized beta coefficients; $+<0.10 ;{ }^{*}<0.05 ;{ }^{* *}<0.01 ;{ }^{* * *}<0.001$.

Table 4. Statistical results for Hypotheses 7-8.

\begin{tabular}{lcccc}
\hline & \multicolumn{2}{c}{ All firms } & Large and medium sized firmsSmall firms & Hypotheses \\
\cline { 2 - 4 } & Model 1 & Model 2 & Model 3 & \\
\hline Constant & -0.027 & -0.010 & 0.037 & \\
Firm age & 0.000 & 0.000 & 0.000 & \\
Firm size & $0.062^{* * *}$ & 0.042 & $0.119+$ & \\
Overall level of components & $0.199^{* * *}$ & $0.211^{* * *}$ & $0.176^{* * *}$ & H7 supported \\
Standard deviation of components & 0.051 & 0.052 & 0.028 & H8 not supported \\
$N$ & 273 & 189 & 84 & \\
R2 & 0.422 & 0.421 & 0.421 & \\
\hline
\end{tabular}

Note. Standardized beta coefficients; $+<0.10 ;{ }^{*}<0.05 ;{ }^{* *}<0.01 ;{ }^{* * *}<0.001$.

not entail lower or higher levels of organizational culture qua viability, because the impact of the standard deviation of the components is not significant (Table 4). Therefore, Hypothesis 8 is not supported. Yet, as the result is nonsignificant, greater or lower deviation among the functional levels of the components also does not harm the organizational culture.

\section{Implications and Synthesis}

In short, the purpose of this contribution was a test of Stafford Beer's VSM, reverting to a larger sample than used to date. This way, we wanted to 
complement earlier work, which had relied on individual case studies, and more recently, relatively small samples. The question posed at the outset was whether the VSM can be refuted, and if not, to what extent it is corroborated by the data.

We have used the construct of organizational culture as a surrogate for viability.

Our analysis has given significant results for six hypotheses; one was neither supported nor rejected, and one was rejected. The test of Hypotheses 1 to 5 demonstrates the following: viability is strongly affected by the levels of development (also, "functional levels") of all components of the VSM, except Component 3 , the operative management of the organization as a whole (Hypothesis 3).

As one potential explanation for the lack of support of Hypothesis 3, we surmise that the negative impact of Component 3, counter to superficial interpretation, does not reflect a loss of importance of the central operative steering function. After all, according to theory, Component 3, in combination with Component 2 , is the lynchpin, or better, the reticulum that sustains the cohesion, which is essential for the viability of an organization. The assumption of deficient measures for Component 3 , in the questionnaire, can be ruled out as a potential explanation, because these, like all the other measures, have been derived carefully from the theory of the VSM (see section "Theory"), a deductive process. However, we assume that, in this case, the measurements were not sufficient to deal with new situations; after some reflection, we believe that a more appropriate interpretation would contend that central operative management, in today's companies, has adopted alternative organizational forms, e.g., team-based, distributed, or virtual structures. In other words, one can presume that Component 3 has not become less important, but that it has evolved new structural solutions. New ways of capturing these will have to be developed in future questionnaires.

The test of Hypotheses 6 to 8 evokes a similar picture as with Hypotheses 1 to 5. It is clearly shown that both the aggregate levels of development of all components and the number of components showing high functional levels are strongly associated with the level of organizational viability. However, the variance of functional levels of components has no impact on viability.

We are getting back to our research questions. Altogether, our study indicates that the claim of the VSM is justified. We have not succeeded in a falsification of Beer's allegation that the model specifies the necessary and sufficient preconditions for the viability of an organization. In conclusion, it must be potentially beneficial to base the diagnosis and design of organizations of any kind, large or small, on that model. The theory of the VSM endows both practitioners and social scientists with a precious, effective conceptual device to enable better organization and management. This is the implication of our study. 
The following limitations of our contribution should not remain unmentioned. First, our measurements have targeted, primarily, the constructs representing Systems 1 to 5. Relationships among these components have been included to a limited extent. This arrangement was meant to avoid too large a questionnaire. In the future, ways should be found to account for these relationships in a more complete fashion.

Second, it might be useful to complement the construct of organizational culture used as an indicator of viability with other indicators. A search for such items is beyond the reach of this study. We also realized a supplementary analysis of three financial indicators. The findings were inconclusive; these variables showed very limited scope and explanatory power, the main reason being their backward-looking focus, since we assessed the financial performance of the past three years. This leads to considerable causality issues that might explain the inconclusive findings. Therefore, we have not pursued this line of inquiry further and encourage future research to study future-oriented financial performance as an outcome measure.

Further heed should be given to a search for new ways of assessing the long-term financial performance of an organization that could be used in the context of a survey that involves nonquoted companies. To date, the literature and current practice give satisfactory answers only for the cases in which samples of quoted companies are used. We surmise that there is no alternative to the analysis of archival data, an alternative that was not existent in the case of our survey.

Third, our analysis does not identify, for System 3, the operative management of the organization as a whole, the importance of which is postulated by the theory. It would be naive and premature to conclude that this component is less important than postulated by theory. Future studies should examine if and how the measurements for System 3 need to and can be improved, in order to capture structural forms that rely increasingly on networks and virtualization.

Fourth, our study has relied on one and the same informant, respectively, for both independent and dependent variables. This should be improved, in the future, by having different informants for each of these two sets of variables.

In its synthesis, this empirical study strongly corroborates the VSM with its underlying theory. This result can encourage practitioners to apply the model to their organizations and researchers to study and test it further. The exploration we have conducted is only a first take. We invite the members of the community of organizational cybernetics to continue this inquiry and engage in the discourse about this topic.

\section{Acknowledgments}

We authors thank Dr. Klaus Edel, Research Unit for Customer Insight at the University of St. Gallen, Switzerland, for his support in the elaboration of the questionnaire and for his help in 
computer-related matters. We are also grateful to Prof. Dr. Robert Neumann, School of Management, Organizational Development and Technology, at the Alpen-Adria-University, Klagenfurt, Austria, for making possible and supporting the collection of data at the 5th Business Management Congress of his Institute.

\section{References}

Adam, M. 2001. Lebensfähigkeit sozialer Systeme: Stafford Beer's viable system model im Vergleich. PhD thesis No. 2442. St. Gallen: University of St. Gallen.

Amey, L. R. 1986. Corporate planning: a systems view. New York, NY: Praeger.

Argyris, C. 1992. On organizational learning. Cambridge, MA: Blackwell.

Ashby, W. R. 1952. Design for a brain: The origin of adaptive behavior. London: Chapman and Hall.

Ashby, W. R. 1956. An introduction to cybernetics. London: Chapman \& Hall.

Baum, J. A. C. (ed.) 2002. The Blackwell companion to organizations. Oxford: Blackwell Publishing.

Beer, S. 1962. Towards the cybernetic factory. In Principles of self-organization, eds. H. von Foerster and G. W. Zopf, 25-89. New York, NY: Pergamon Press.

Beer, S. 1964. Cybernetics and management. New York: Wiley.

Beer, S. 1970. The organization of the Manchester business school from nineteen seventy. Manchester: Business School.

Beer, S. 1979. The heart of enterprise. Chichester: Wiley.

Beer, S. 1981. The brain of the firm. Chichester: Wiley.

Beer, S. 1984. The viable system model: Its provenance, development, methodology and pathology. Journal of the Operational Research Society 35 (1):7-25. doi:10.2307/ 2581927

Beer, S. 1985. Diagnosing the system for organizations. Chichester: Wiley.

Beer, S. 1989. National government: Disseminated regulation in real time or "how to run a country." In The viable system model - Interpretations and applications of Stafford Beer's VSM, eds. R. Espejo and R. J. Harnden, 333-60. New York, NY: Wiley.

Berman, S. 2012. How corporate culture will change in the face of openness. http://www. foxbusiness.com/business-leaders/2012/05/21/how-corporate-cultures-will-change-in-faceunstoppable-trend-openness/ (accessed May 6, 2016).

Bleuel, W., and D. J. Stanley. 2007. Customer focus: One key to financial success. Business Renaissance Quarterly 2 (2):41-9.

Bolman, L. G., and T. E. Deal. 1991. Modern approaches to understanding and managing organizations (2nd ed.). San Francisco, CA: Jossey-Bass.

Bontis, N., M. Crossan, and J. Hulland. 2002. Managing an organizational learning system by aligning stocks and flows. Journal of Management Studies 39 (4):437-69. doi:10.1111/14676486.t01-1-00299

Bowles, S., and H. Gintis. 2011. A cooperative species: Human reciprocity and its evolution. Princeton, NJ: Princeton University Press.

Brocklesby, J., and S. Cummings. 1996. Designing a viable organization structure. Long Range Planning 29 (1):49-57. doi:10.1016/0024-6301(95)00065-8

Brundtland, G. H. 1987. Our common future. The world commission on environment and development. New York, NY: Oxford University Press.

Burns, T., and G. M. Stalker. 2001. The management of innovation. Reprint (originally published 1961). Oxford: Oxford University Press. 
Chadwick, C., and J. F. K. Super. 2014. Resource orchestration in practice: CEO emphasis on SHRM, commitment-based HR systems, and firm performance. Strategic Management Journal 36 (3):360-76. doi:10.1002/smj.2217

Christopher, W. F. 2007. Holistic management: Managing what matters for company success. Hoboken, NJ: Wiley.

Churchman, C. W. 1968. Challenge to reason. New York, NY: McGraw-Hill.

Crisan Tran, C. I. 2006. Beers viable system model und die Lebensfähigkeit von Jungunternehmen - Eine empirische Untersuchung. PhD thesis, No. 3201. St. Gallen, Switzerland: University of St. Gallen.

Deal, T. E., and A. A. Kennedy. 1982. Corporate cultures: The rites and rituals of corporate life. Reading, MA: Addison-Wesley.

de Geus, A. 1997. The living company. London: Nicholas Brealey.

Drucker, P. F. 2001. The essential Drucker. New York, NY: Harper Business.

Eagleton, T. 2000. The idea of culture. Malden, MA: Blackwell Publishing.

Elezi, F., I. D. Tommelein, W. Bauer, M. Maurer, and U. Lindemann. 2014. A viable system model perspective on variant management based on a structural complexity management approach. In Risk and change management in complex systems. Proceedings of the 16th international DSM conference, eds. F. Marle, M. Jankovic et al., 13-19. Munich, Germany: Hanser.

Espejo, R., and R. J. Harnden (eds.). 1989. The viable system model. Interpretations and applications of Stafford Beer's VSM. Chichester: Wiley.

Espejo, R., and A. Reyes 2011. Organizational systems: Managing complexity with the viable system model. Berlin: Springer.

Espejo, R., W. Schuhmann, M. Schwaninger, and U. Bilello. 1996. Organizational transformation and learning: A cybernetic approach to management. Chichester: Wiley.

Espinosa, A., R. Harnden, and J. Walker. 2008. A complexity approach to sustainability Stafford Beer revisited. European Journal of Operational Research 187:636-51. doi:10.1016/j.ejor.2007.03.023

Espinosa, A., and J. Walker. 2006. Environmental management revisited: Lessons from a cybernetic intervention in Colombia. Cybernetics and Systems: An International Journal 37 (1):75-92. doi:10.1080/01969720591008724

Espinosa, A., and J. Walker. 2011. A complexity approach to sustainability. Theory and application. London: Imperial College Press.

Espinosa, A., and J. Walker. 2013. Complexity management in practice: A viable system model intervention in an Irish eco-community. European Journal of Operational Research 225:11829. doi:10.1016/j.ejor.2012.09.015

Foster, R. N., and S. Kaplan. 2001. Creative destruction: Why companies that are built to last underperform the market - and how to successfully transform them. New York, NY: Currency.

Frost, B. 2005. Lebensfähigkeit von Communities of Practice im organisationalen Kontext. Dissertation. PhD thesis, No. 3120. St. Gallen, Switzerland: University of St. Gallen.

Gälweiler, A. 2005. Strategische Unternehmensführung (3rd ed.). Frankfurt a.M./New York, NY: Campus.

Gmür, B., A. Bartelt, and R. Kissling. 2010. Organization from a systemic perspective: Application of the viable system model to the Swiss youth hostel association. Kybernetes 39 (9-10):1627-44. doi:10.1108/03684921011081204

Gómez Roldán, I., and R. G. R. Bray. 2009. Similarities and differences existing in cultural profiles of Colombian organizations of higher and lower performance. Revista Facultad de Ciencias Económicas XVII (1):9-24.

Grisaffe, D. B., and F. Jaramillo. 2007. Toward higher levels of ethics: Preliminary evidence of positive outcomes. Journal of Personal Selling \& Sales Management 27 (4):355-71. doi:10.2753/pss0885-3134270406 
Haasis, H. 2007. Mittelstand hat Zukunft Praxishandbuch für eine erfolgreiche Unternehmenspolitik. Wiesbaden: Gabler.

Hameseder, J., and S. Zach. 2013. Leistungs- und Strukturstatistik. Produktion \& Dienstleistungen. Vienna, Austria: Statistik Austria.

Harmon, F. G., and G. Jacobs. 1985. The vital difference. Unleashing the powers of sustained corporate success. New York, NY: AMACOM - American Management Association.

Hatch, M. J. 1997. Organization theory. Modern symbolic and postmodern perspectives. Oxford: Oxford University Press.

Herrmann, C., L. Bergmann, P. Halubek, and T. Sebastian. 2008. Lean production system design from the perspective of the viable system model. In Manufacturing systems and technologies for the new frontier: The 41st CIRP conference on manufacturing systems, 2008, Tokyo, Japan, eds. M. Mitsuishi, K. Ueda, and F. Kimura, 309-12. London: Springer.

Heskett, J. 2012. The culture cycle: How to shape the unseen force that transforms performance. Upper Saddle River, NJ: FT Press.

Hofstede, G. 1980. Culture's consequences: International differences in work-related values. London: Sage Publications.

Hoverstadt, P. 2008. The fractal organization. Creating sustainable organizations with the viable system model. Chichester: Wiley.

Jackson, M. C. 1988. An appreciation of Stafford Beer's “viable system." Viewpoint on managerial practice. Journal of Management Studies 25 (6):557-73.

Jackson, M. C. 2000. Systems approaches to management. New York, NY: Kluwer Academic/ Plenum.

Jackson, R. W., C. M. Wood, and J. J. Zboja. 2013. The dissolution of ethical decision-making in organizations: A comprehensive review and model. Journal of Business Ethics 116:233-50. doi:10.1007/s10551-012-1459-3

Jantsch, E. 1980. The self-organizing universe: Scientific and human implications of the emerging paradigm of evolution. Oxford: Pergamon Press.

Kant, I. 1911. Grundlegung der Metaphysik der Sitten. In Kant's Werke, Band IV, ed. Königliche Preussische Akademie der Wissenschaften, 385-463. Berlin: Verlag Georg Reimer.

Koontz, H. 1961. The management theory jungle. Academy of Management Journal 4 (3): 174-88. doi:10.2307/254541

Koontz, H. 1980. The management theory jungle revisited. The Academy of Management Review 5 (2):175-87. doi:10.5465/amr.1980.4288715

Kotter, J., and J. Heskett. 1992. Corporate culture and performance. New York, NY: Free Press.

Lawrence, P. R., and J. W. Lorsch. 1967. Organization and environment: Managing differentiation and integration. Boston, MA: Division of Research, Graduate School of Business Administration, Harvard University.

Leonard, A. 1989. Application of the VSM to commercial broadcasting in the United States. InThe viable system model. Interpretations and applications of Stafford Beer's VSM, eds. R. Espejo and R. J. Harnden 175-209. Chichester: Wiley.

Leonard, A. 2010. Advancing viable governance. General Systems Bulletin 39:5-11.

Malik, F. 2008. Strategie des Managements komplexer Systeme. Ein Beitrag zur ManagementKybernetik evolutionärer Systeme (10th ed.). Bern: Paul Haupt.

May, P. 2012. Erfolgsmodell Familienunternehmen. Das Strategie-Buch. Hamburg: Murmann.

Meadows, D. H., D. L. Meadows, and J. Randers. 1972. The limits to growth. London: Universe Books.

Mitchell, M. 2009. Complexity. A guided tour. New York, NY: Oxford University Press. 
Moon, H., N. R. Quigley, and J. C. Marr. 2012. How interpersonal motives explain the influence of organizational culture on organizational productivity, creativity, and adaptation: The ambidextrous interpersonal motives (AIM) model of organizational culture. Organizational Psychology Review 2:109-128. doi:10.1177/2041386611433085

Morgan, G. 2006. Images of organization (Updated edition). Thousand Oaks, CA: Sage.

Pérez Ríos, J. 2012. Design and diagnosis for sustainable organizations: The viable system method. Berlin: Springer.

Pfeffer, J. 1997. New directions for organization theory: Problems and prospects. New York, NY: Oxford University Press.

Pfeffer, J. 2010. Building sustainable organizations: The human factor. Academy of Management Perspectives 24 (1):34-45.

Popper, K. R. 1972. Objective knowledge: An evolutionary approach. Oxford: Clarendon Press. Popper, K. R. 2002. The logic of scientific discovery. London: Routledge.

Preece, G., D. Shaw, and H. Hayashi. 2013. Using the viable system model (VSM) to structure information processing complexity in disaster response. European Journal of Operational Research 224 (1):209-18. doi:10.1016/j.ejor.2012.06.032

Rapoport, A. 1986. General System Theory. Essential Concepts and Applications. London: Abacus.

Rapoport, A. 1998. Decision theory and decision behaviour (2nd revised ed.). Houndmills: Macmillan.

Reissberg, A. C. 2010. A cybernetic approach to hurricane hazard management on O'ahu, Hawai'i. PhD thesis. Manoa, Hawaii: University of Hawai'i.

Schein, E. H. 1984. Coming to a new awareness of organizational culture. Sloan Management Review 25 (2):3-16.

Schein, E. H. 2010. Organizational culture and leadership (4th ed.). San Francisco, CA: Jossey-Bass.

Schwaninger, M. 1989. Integrale Unternehmensplanung. Frankfurt/Main and New York: Campus.

Schwaninger, M. 2006a. Design for viable organizations: The diagnostic power of the viable system model. Kybernetes 35 (7-8):955-66. doi:10.1108/03684920610675012

Schwaninger, M. 2006b. The quest for ecological sustainability: A multi-level issue. In Proceedings of the seventeenth European meeting on cybernetics and systems research, ed. R. Trappl, 149-54. Vienna: University of Vienna and Austrian Society for Cybernetic Studies.

Schwaninger, M. 2009. Intelligent organizations: Powerful models for systemic management (2nd ed.). Berlin: Springer.

Schwaninger, M. 2012. Making change happen: Recollections of a systems professional. Kybernetes 41 (3):348-67. doi:10.1108/03684921211229451

Schwaninger, M. 2015. Organizing for sustainability: A cybernetic concept for sustainable renewal. Kybernetes 44 (6-7):935-54. doi:10.1108/k-01-2015-0008

Schwaninger, M., and T. Friedli. 2011. Zur Lebensfähigkeit virtueller Organisationen. In Managementsysteme. Die Flexibilisierung und virtuelle Öffnung der Unternehmung, eds. K. Bleicher and C. Abegglen, 209-33. Künzelsau, Germany: Swiridoff Verlag.

Schwaninger, M., and M. Koerner. 2004. City planning - "Dissolving" urban problems. Insights from an application of management cybernetics. Kybernetes 33 (3-4):557-76. doi:10.1108/03684920410523571

Schwaninger, M., and J. Pérez Ríos. 2008. System dynamics and cybernetics: A synergetic pair. System Dynamics Review 24 (2):145-74. doi:10.1002/sdr.400

Scott, W. R., and G. F. Davis. 2007. Organizations and organizing: Rational, natural, and open systems perspectives. Upper Saddle River, NJ: Pearson Education Inc. 
Seiffert, H., and G. Radnitzky. 1974. Handlexikon der Wissenschaftstheorie (2nd ed.) München: Deutscher Taschenbuch Verlag.

Senge, P. M. 1990. The fifth discipline: The art and practice of the learning organization. London: Century Business.

Shook, C. L., D. J. Ketchen Jr., G. T. M. Hult, and K. M. Kacmar. 2004. An assessment of the use of structural equation modeling in strategic management research. Strategic Management Journal 25 (4):397-404.

Simpson, J. A., and E. S. C. Weiner. 1989. The Oxford English dictionary. Oxford: Clarendon Press.

Sims, D., S. Fineman, and Y. Gabriel. 1993. Organization \& organizations. An introduction. London: Sage.

Sterman, J. D. 2000. Business dynamics. Systems thinking and modeling for a complex world. Boston, MA: Irwin/Mc Graw-Hill.

Strunk, G. 2011. Sind Familienunternehmer die besseren Unternehmer oder gar die besseren Menschen? HWWI (Hamburgisches WeltWirtschaftsInstitut, Hamburg) INSIGHTS 3.

Tabachnick, B. G., and L. S. Fidell. 1996. Using multivariate statistics. New York, NY: HarperCollins.

Türke, R.-E. 2008. Governance. Systemic foundation and framework. Heidelberg: PhysicaVerlag.

Ulrich, P. 2010. Integrative economic ethics: Foundations of a civilized market economy. Cambridge: Cambridge University Press.

Ulrich, W. 1983. Critical heuristics of social planning: A new approach to practical philosophy. Bern: Haupt.

Von Bertalanffy, L. 1968. General system theory. Foundations, development, applications. New York, NY: Braziller.

Willemsen, M. H. 1992. Ist die Schweiz ein lebensfähiges System? Kybernetische Diagnose des schweizerischen politischen Systems. Chur/Zürich: Rüegger.

Woodford, M. 2014. Corporate ethics are a matter of life and death. In http://www.ft.com/intl/ cms/s/0/6cca2bec-19d6-11e2-a379-00144feabdc0.html\#axzz3IqGf6WEM (accessed July 1, 2015).

Wuffli, P. A. 2016. Inclusive leadership. A framework for the global era. Cham, Switzerland: Springer. 


\section{Appendix I: The Viable System Model}

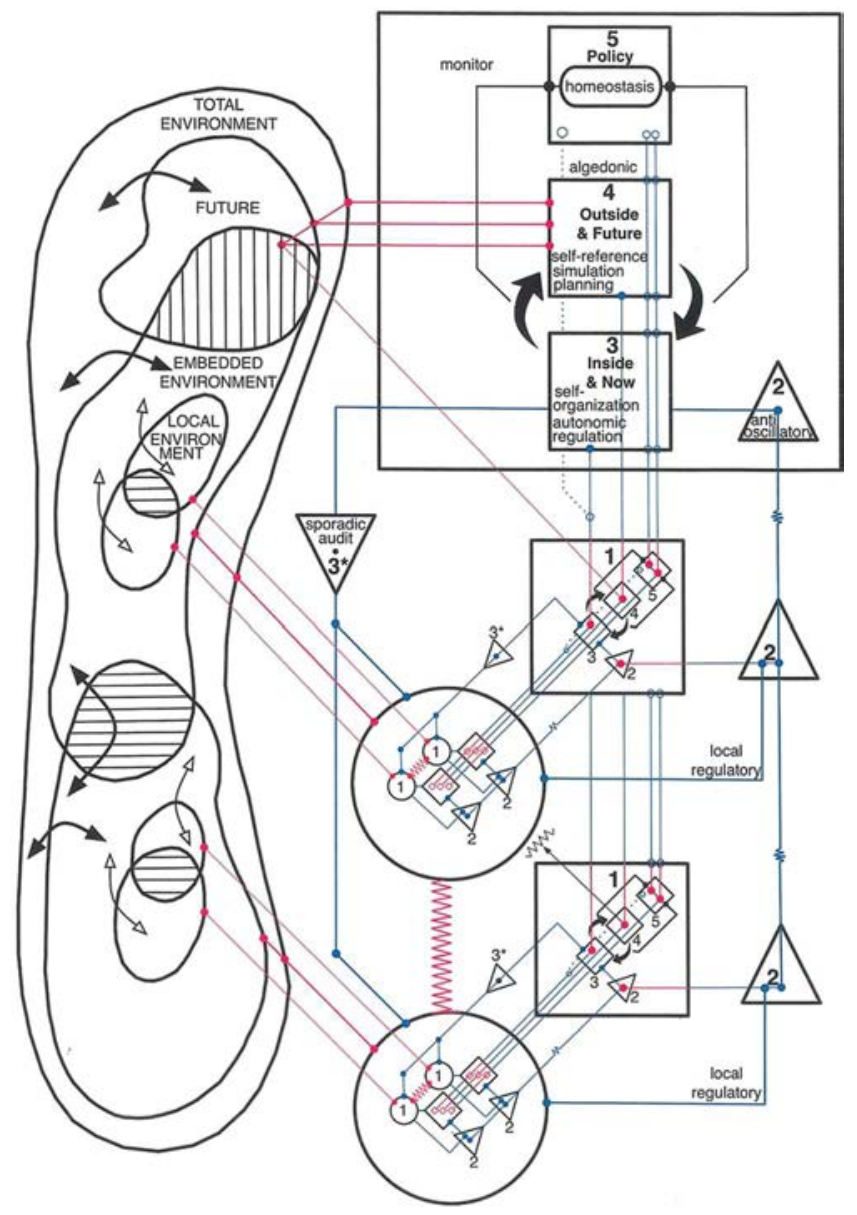

*Source: Beer (1985, 136). Drawn by Ivan Ulyanov.

\section{Appendix II: List of Items from Questionnaire}

\begin{tabular}{ll}
\hline & \multicolumn{1}{c}{ Independent Variables } \\
\hline Component 1 & Management of Basic Units \\
F0421 & Is responsible for profit and loss \\
F0422 & Is responsible for market position \\
F0423 & Is responsible for investments \\
F0424 & Is responsible for human resources \\
F0430 & Level of autonomy \\
Component 2 & Coordination Mechanisms and Instruments Used \\
F0511 & Regular meetings \\
F0512 & Spontaneous meetings \\
F0513 & Reporting \\
F0514 & Operative planning \\
F0515 & Sector-transcending teams \\
F0521 & Quality and environmental standards \\
\hline
\end{tabular}




\begin{tabular}{|c|c|}
\hline F0522 & Shared values \\
\hline F0523 & Orientation by shared principles and rules \\
\hline Component 3 & Operative Corporate Management \\
\hline F0611 & Corporate Management negotiates binding goals with the operative units \\
\hline F0612 & Attainment of goals regularly checked by Corporate Management \\
\hline F0613 & $\begin{array}{l}\text { Alarm thresholds for basic units have been defined, infringement of which is } \\
\text { reported to Corporate Management }\end{array}$ \\
\hline F0614 & Resources are allocated to basic units by Corporate Management \\
\hline F0615 & Synergies between basic units are realized well \\
\hline F0621 & Information of financial accounting to Corporate Management by basic units \\
\hline F0622 & Information of cost accounting to Corporate Management by basic units \\
\hline F0623 & Information of liquidity status to Corporate Management by basic units \\
\hline F0624 & Information of production control to Corporate Management by basic units \\
\hline Component $3^{*}$ & Auditing/Monitoring Mechanisms and Processes Used \\
\hline F0711 & Internal Auditing \\
\hline F0712 & Management audits \\
\hline F0713 & Special studies or surveys \\
\hline F0714 & 'Management by Wandering Around' \\
\hline F0721 & Cultural events (sports, excursions, etc.) \\
\hline F0722 & Informal meetings of managers and staff (coffee, lunch, etc.) \\
\hline Component 4 & Strategy/Corporate Development \\
\hline F0810 & Observation of important external factors to check strategy \\
\hline F0821 & Systematic checking of internal future \\
\hline F0822 & Systematic checking of external future \\
\hline F0823 & Adaptation of strategy as a consequence of these checks \\
\hline F0824 & Persons from different organizational units partake in strategy-making \\
\hline F0825 & $\begin{array}{l}\text { The Management conceives of strategy as a task in its own right (not to be } \\
\text { confused with the operative) }\end{array}$ \\
\hline F0826 & Extraordinary ideas are promoted especially \\
\hline Component 5 & Normative Management/Ethos \\
\hline F0911 & Company has clearly formulated principles (norms, values, mission) \\
\hline F0912 & These principles are met by all members of the company/business unit \\
\hline F0913 & $\begin{array}{l}\text { Measures for the assessment of the company/business unit as a whole have } \\
\text { been derived }\end{array}$ \\
\hline F0914 & Corporate principles are regularly overhauled \\
\hline F0915 & $\begin{array}{l}\text { Long-term/normative issues/problems are treated in distinction of the } \\
\text { short-term ones }\end{array}$ \\
\hline \multicolumn{2}{|r|}{ Dependent Variables } \\
\hline \multicolumn{2}{|l|}{ Financial Indices } \\
\hline F210 & Nominal growth rate of business volume, average $\%$ last four years \\
\hline F220 & $\begin{array}{l}\text { Evolution of business volume of company/business unit, compared with } \\
\text { industry average, last two years }\end{array}$ \\
\hline F230 & $\begin{array}{l}\text { Change of percentage share of equity on total capital, over } \\
\text { last } 10 \text { years or since foundation of company }\end{array}$ \\
\hline Cultural Indices & Polarities of features shown by company culture \\
\hline F310 & Open-Closed \\
\hline F311 & Adaptive-Unadaptive \\
\hline F312 & Learning-Nonlearning \\
\hline F313 & Moral-Immoral \\
\hline F314 & Cooperative-Egoistic \\
\hline F315 & Coherent-Incoherent \\
\hline F316 & Customer-oriented-Self-centered \\
\hline F317 & Modest-Arrogant \\
\hline F318 & Long-term oriented-Short-term oriented \\
\hline F319 & Socially responsible-Socially irresponsible \\
\hline F320 & Ecologically responsible-Ecologically irresponsible \\
\hline
\end{tabular}




\section{Appendix III: Measurement of Items for Culture}

\section{Measuring Example Cultural Indices (Extract from the original questionnaire)}

The question is: "How would you characterize the culture of your company or business unit?" The measurement follows Osgood's method of semantic differentials. The pairs of terms are translated into English in Appendix III.

\begin{tabular}{|c|c|c|c|c|c|c|}
\hline 3. KULTUR & & & & & & \\
\hline 3.1. Wie schätzen Sie c & in & Unt & nun & $\mathrm{G}$ & tsei & it ein? \\
\hline offen & $\square$ & $\square$ & $\square$ & $\square$ & $\square$ & geschlossen \\
\hline anpassungsfähig & $\square$ & $\square$ & $\square$ & $\square$ & $\square$ & nicht anpassungsfähig \\
\hline lernfähig & $\square$ & $\square$ & $\square$ & $\square$ & $\square$ & nicht lernfähig \\
\hline moralisch & $\square$ & $\square$ & $\square$ & $\square$ & $\square$ & unmoralisch \\
\hline kooperativ & $\square$ & $\square$ & $\square$ & $\square$ & $\square$ & egoistisch \\
\hline kohärent & $\square$ & $\square$ & $\square$ & $\square$ & $\square$ & zersplittert \\
\hline kundenorientiert & $\square$ & $\square$ & $\square$ & $\square$ & $\square$ & selbstzentriert \\
\hline bescheiden / dienend & $\square$ & $\square$ & $\square$ & $\square$ & $\square$ & arrogant \\
\hline langfristig orientiert & $\square$ & $\square$ & $\square$ & $\square$ & $\square$ & kurzfristig orientiert \\
\hline $\begin{array}{l}\text { sozial verantwortlich } \\
\text { ökologisch }\end{array}$ & $\square$ & $\square$ & $\square$ & $\square$ & $\square$ & $\begin{array}{l}\text { sozial unverantwortlich } \\
\text { ökologisch }\end{array}$ \\
\hline verantwortlich & $\square$ & $\square$ & $\square$ & $\square$ & $\square$ & unverantwortlich \\
\hline
\end{tabular}

